Marquette University

e-Publications@Marquette

$5-2016$

\title{
Perceptions of Blame in Intimate Partner Violence: The Role of the Perpetrator's Ability to Arouse Fear of Injury in the Victim
}

\author{
Brenda Russell \\ The Pennsylvania State University \\ Shane W. Kraus \\ Yale University \\ Kristine M. Chapleau \\ Marquette University \\ Debra Oswald \\ Marquette University, debra.oswald@marquette.edu
}

Follow this and additional works at: https://epublications.marquette.edu/psych_fac

Part of the Psychology Commons

\section{Recommended Citation}

Russell, Brenda; Kraus, Shane W.; Chapleau, Kristine M.; and Oswald, Debra, "Perceptions of Blame in Intimate Partner Violence: The Role of the Perpetrator's Ability to Arouse Fear of Injury in the Victim" (2016). Psychology Faculty Research and Publications. 211.

https://epublications.marquette.edu/psych_fac/211 
Marquette University

\section{e-Publications@Marquette}

\section{Psychology Faculty Research and Publications/ Psychology Department}

This paper is NOT THE PUBLI SHED VERSI ON; but the author's final, peerreviewed manuscript. The published version may be accessed by following the link in the citation below.

Journal of Interpersonal Violence, (May 2016): 1-9. DOI. This article is (C) SAGE Publications and permission has been granted for this version to appear in ePublications@Marquette. SAGE Publications does not grant permission for this article to be further copied/distributed or hosted elsewhere without the express permission from SAGE Publications.
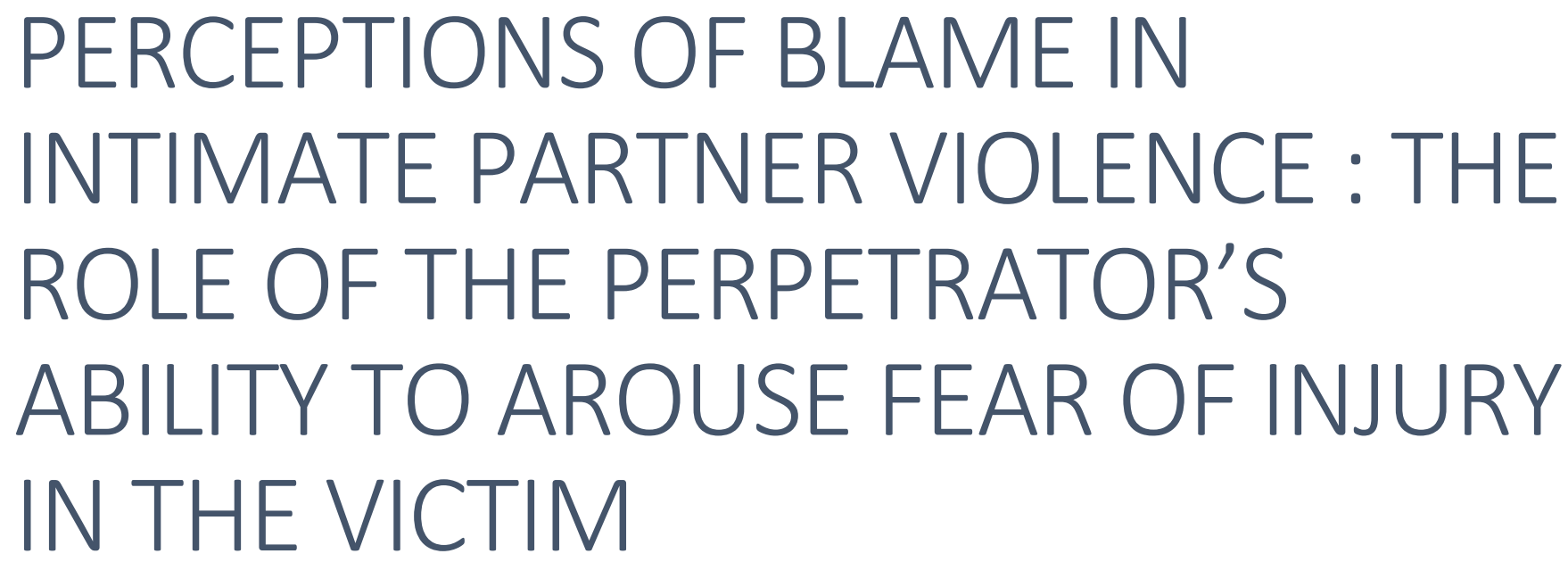

Brenda Russell

The Pennsylvania State University, Berks, PA

Shane W. Kraus

VA Connecticut Healthcare System, West Haven, CT

Yale University, New Haven, CT

Kristine M. Chapleau

Indiana University, Bloomington, IN

Debra Oswald

Marquette University, Milwaukee, WI 


\section{Abstract}

Men are more likely to be blamed more for intimate partner violence (IPV) than are women who commit the same offense. However, because men are typically stronger and perceived as more physically aggressive than women are, perpetrator sex is confounded with masculinity and the ability to arouse fear in the victim. This study disentangled the construct of gender in understanding bystanders' attributions of blame in IPV. Participants $(N=639)$ read a scenario in which the perpetrator's sex (male/female) and gender identity (masculine/feminine), and the victim's sex (male/female) were manipulated and rated how much they blamed the perpetrator and the perpetrator's ability to arouse fear of injury in the victim. Results showed that male perpetrators (regardless of gender identity) who assaulted a female victim were attributed the most blame and were perceived as having the greatest ability to arouse victim fear. In contrast, feminine female perpetrators were attributed the least blame and perceived as arousing the least victim fear regardless of the victim's gender. Furthermore, controlling for the perpetrator's ability to arouse fear in the victim resulted in the elimination of the interaction effects for blame. This finding suggests that perpetrators' ability to arouse fear is an underlying factor in bystanders' attributions of blame.

Keywords $\underline{\text { blame, }}$ injury, partner violence, perpetrator sex, victim sex, gender identity, $\underline{\text { masculinity/femininity }}$

Intimate partner violence (IPV) is a serious social problem affecting millions in the United States (Black et al., 2011). Research suggests that men and women in heterosexual and same-sex relationships are equally likely to perpetrate (Straus, 2010) or to be victims of IPV (West, 2012). The majority of IPV between partners is bidirectional (57.9\%; Langhinrichsen-Rohling, Misra, Selwyn, \& Rohling, 2012). Among reports of unidirectional violence $(42.1 \%)$, approximately $14 \%$ was male-to-female and $28 \%$ was female-to-male; these rates were comparable between heterosexual and same-sex couples. Female perpetrators do inflict injuries, and male victims are often injured (Douglas \& Hines, 2011; Laroche, 2005). Despite these findings, male-to-female IPV is perceived as more serious than female-to-male or same-sex IPV (Felson \& Feld, 2009; Hamby \& Jackson, 2010; Russell, Ragatz, \& Kraus, 2012; Seelau \& Seelau, 2005), and resources for male and lesbian IPV victims are limited (Douglas \& Hines, 2011).

One reason this discrepancy exists may be that IPV that results in injury is considered more serious than when injuries do not occur (Katz \& Arias, 2001). Furthermore, male perpetrators are perceived as more capable of inflicting injury (Rhatigan, Stewart, \& Moore, 2011), whereas female victims are perceived as more vulnerable to injury (Seelau \& Seelau, 2005). However, these perceived sex differences are confounded with gender identity (masculinity/femininity), stereotypes about aggressiveness (Spence \& Helmreich, 1979), and the ability to arouse fear of injury in another. We postulate that judgments about IPV blame are based on the perpetrator's ability to arouse fear of injury in the victim, which is driven more by gendered assumptions than the perpetrator's sex.

\section{The Current Study}

This study expands previous research by manipulating the sex (male/female) and gender identity (masculinity/femininity) of the perpetrator as well as the sex of the victim (male/female). Participants' sex was also included as a variable. We had the following hypotheses: 
- Hypothesis H1a: Male perpetrators who assaulted female victims would be blamed more and rated as inciting more victim fear of physical injury.

- Hypothesis H1b: Feminine female perpetrators would evoke the least fear of injury, whereas masculine male perpetrators would arouse the most fear of victim injury.

- Hypothesis H1c: When the victim was female, masculine male perpetrators would be blamed more and rated as arousing greater fear of injury in the victim compared with feminine male perpetrators.

- Hypothesis H2: Any significant interactions found for perpetrator blame would be reduced or eliminated when perceived victim fear of injury was statistically controlled.

\section{Method}

\section{Design and Procedure}

Participants were randomly assigned to read one of eight scenarios that manipulated perpetrator sex, perpetrator gender identity, and victim sex. Participant sex was included as a variable, and participant age and sample type (student and online sample) were included as covariates. All conditions were randomized, and responses were anonymous.

\section{Participants}

The student sample was comprised of 263 students ( 114 males, $43.4 \%$, and 149 females, $56.6 \%$ ) enrolled in psychology classes from a Northeastern University in the United States with an age range of 18 to 50 and a mean of $18.86(S D=1.46)$. The online sample was recruited using Mechanical Turk and included 376 participants, 221 (58.8\%) males and 155 (41.2\%) females between the ages of 18 and 72, with a mean age of $36.09(S D=12.74)$. The majority of the student sample $(93.5 \%)$ and online sample $(94.7 \%)$ reported they were heterosexual.

\section{Materials}

\section{Case scenario}

Participants read one of eight scenarios depicting an incident of IPV. The scenario described a neighbor as hearing the perpetrator threatening to kill the victim and then witnessing the perpetrator chasing the victim with a knife. The victim attempts to calm the perpetrator down while leaving the scene. The perpetrator prevents the victim from leaving, and a physical altercation ensues that ends with blood seen on the victim.

\section{Perpetrator/victim sex}

Gender of the characters was manipulated through the names of the perpetrator (David, Jennifer) and victim (Henry, Charlene).

\section{Perpetrator gender identity}

Gender identity was conveyed through adjectives and color photographs of the perpetrator and his or her place of employment. Masculine perpetrators were described as "powerful" and portrayed as a construction worker sawing wood on a construction site. Feminine perpetrators were described as "emotional and affectionate" and shown as a schoolteacher standing near a blackboard. Participants rated the perpetrator on perceived masculinity/femininity $(1=$ feminine and $7=$ masculine $)$. The perpetrator was rated as more masculine $(\mathrm{M}=$ $5.56, S D=1.20)$ in masculine than in the feminine condition $(M=4.20, S D=1.59), t(628)=12.05, p<.0001$, Cohen's $d=0.97$. 
Perpetrator blame, ability to arouse fear of physical injury, and demographics Ratings for blame were assessed using a 7-point scale ( $1=$ not at all to $7=$ completely). Items included (a) the extent to which the perpetrator was responsible, (b) "the perpetrator was to blame," (c) "the perpetrator should be charged," (d) threatened bodily injury to the victim, and (e) degree of seriousness of the incident. A principal components factor analysis showed all five items loaded onto one factor (eigenvalue $=2.81$ ) and accounted for $56.25 \%$ of the total variance. Cronbach's alpha was .80 . To assess victim's fear of bodily injury, participants were asked, "Please rate the degree to which you believe (victim name: Charlene/Henry) feared bodily injury" ( $1=$ not at all and 7 = completely). Demographic information was assessed, including age, gender, sexual orientation, and education level.

\section{Results}

\section{Descriptive Statistics}

Fourteen individuals were removed from analyses because of incomplete data or inaccurate identification of the couple's sexual orientation. Participants' age, $r(610)=.11, p<.01, r^{2}=.1$, and ratings of perpetrators' ability to arouse fear, $r(623)=.53, p<.001, r^{2}=.28$, positively correlated with perpetrator blame. The online sample had significantly higher mean scores on blame $(M=5.79, S D=1.01)$ than the student sample $(M=5.61, S D=0.86)$, $t(623)=-2.43, p=.01$, but the two groups did not differ in perceptions of victim fear of injury, $t(623)=-1.00, p$ $=.31$. Participant age and sample type were used as covariates in the following analyses.

\section{Perpetrator Blame and Ability to Arouse Fear of Injury}

A 2 (perpetrator sex) $\times 2$ (perpetrator masculinity/femininity) $\times 2$ (victim sex) $\times 2$ (participant sex) betweensubjects MANCOVA was computed using perpetrator blame and victim fear of bodily injury as the dependent variables. Neither age, $F(1,635)=1.37, p=.25$, nor sample type, $F(1,635)=1.87, p=.15$ was a statistically significant covariate.

There were no main effects for participant sex, perpetrator sex, or perpetrator masculinity/femininity. However, there was a significant multivariate main effect for victim $\operatorname{sex}, F(1,635)=4.89, p<.01, \eta^{2}{ }_{p}=.01$. Univariate follow-ups showed that blame was significantly higher when the victim was female $(M=5.79, S D=0.90)$ than male $(M=5.64, S D=0.98), F(1,635)=4.57, p<.05, \eta^{2}{ }_{p}=.007$. Similarly, the perpetrator's ability to arouse fear of injury was significantly greater for female victims $(M=6.31, S D=1.17)$ than male victims $(M=5.99, S D=$ 1.45), $F(1,635)=9.40, p<.05, \eta^{2}{ }_{p}=.01$.

There was also a significant Perpetrator Sex $\times$ Victim Sex interaction, $F(1,635)=7.35, p<.05, \eta_{p}^{2}=.02$. Univariate ANOVAs provided support for Hypothesis 1a showing perpetrator ratings of blame were highest when the perpetrator was male and victim was female $(M=5.96, S D=0.82)$ compared with male perpetrator/male victim $(M=5.57, S D=1.05)$, female perpetrator/female victim $(M=5.63, S D=0.96)$, or female perpetrator/male victim $(M=5.72, S D=0.90), F(1,635)=11.95, p<.05, \eta_{p}^{2}=.02$. Univariate results were also significant for victim fear of bodily injury, $F(1,635)=10.44, p<.05, \eta^{2}=.01$. Victim fear of bodily injury was highest for male perpetrator/female victim $(M=6.58, S D=0.80)$ compared with male perpetrator/male victim $(M=5.94, S D=1.56)$, female perpetrator/female victim $(M=6.07, S D=1.37)$, or female perpetrator/male victim $(M=6.07, S D=1.31)$. There were no other significant differences among same-sex couples or heterosexual females. 
The Perpetrator Sex $\times$ Perpetrator Gender Identity (masculinity/femininity) interaction was also significant (Hypothesis $\mathrm{H} 1 \mathrm{~b}), F(1,635)=9.40, p<.05, \eta^{2}{ }_{\mathrm{p}}=.01$. Univariate tests revealed significant interaction effects for blame, $F(1,635)=6.29, p<.05, \eta_{p}{ }_{p}=.01$, and victim fear of bodily injury, $F(1,635)=9.54, p<.05, \eta_{p}^{2}=.015$. Feminine female perpetrators had significantly lower ratings of blame $(M=5.51, S D=1.00)$ compared with masculine males $(M=5.75, S D=0.97)$, feminine males $(M=5.76, S D=0.82)$, and masculine female perpetrators $(M=5.83, S D=0.82)$. Similarly, feminine female perpetrators induced significantly less fear of victim injury $(M=$ $5.88, S D=1.51)$ compared with masculine male $(M=6.12, S D=1.36)$, feminine male $(M=6.34, S D=1.24)$, and masculine female perpetrators $(M=5.88, S D=1.10)$. No other significant main effects or interactions were found.

In an effort to determine whether perceptions of fear of injury to the victim (Hypothesis 2) could account for the interaction effects between the independent variables of perpetrator sex, perpetrator gender identity, and victim sex, we included fear of bodily injury as a covariate into the factorial model. Blame was the dependent variable. Covariates age and sample type were not statistically significant; however, the covariate fear of injury was highly significant, $F(1,597)=215.12, p<.0001, \eta_{p}^{2}=.26$. When the covariate was included in the model, the strength of the Perpetrator Sex $\times$ Victim Sex interaction was reduced to $F(1,597)=4.32, p=.04, \eta_{p}^{2}=.01$, and the Perpetrator Sex $\times$ Perpetrator Gender Identity (masculinity/femininity) interaction was no longer statistically significant, $F(1,597)=1.09, p=.29$.

\section{Discussion}

This study expanded upon previous research by disentangling the role of sex and gender identity in people's evaluations of blame and perceived victim fear of injury in IPV.

Consistent with previous research, this study found blame and the perpetrator's ability to arouse fear of injury in the victim were highest when the victim was female (Rhatigan et al., 2011; Seelau \& Seelau, 2005). Also in line with previous research (Russell et al., 2012; Seelau \& Seelau, 2005), results found male perpetrators who assaulted females received significantly higher ratings of blame and incited the most fear of injury in the victim compared with all other conditions. These results suggest male-to-female IPV is considered more serious, supporting the belief that women (particularly heterosexual women) are more vulnerable and in need of protection than men. This may also be an artifact of the gender-role belief that men are strong and aggressive and ultimately better equipped to protect themselves from a female perpetrator.

As predicted, interaction effects also showed feminine female perpetrators had significantly lower ratings of blame and were least likely to arouse fear of injury in the victim. The lack of a three-way interaction between perpetrator sex and masculinity/femininity and victim sex for blame suggests that blame was not necessarily a function of perpetrator or victim sex, but rather the femininity and/or masculinity of the perpetrator of IPV. These results reveal that gender-role identity appears to play a larger role for female perpetrators than it does for male perpetrators. In essence, our benevolent sexist ideals about femininity provide protection for feminine women, but there seem to be no advantage for men who demonstrate the same feminine traits. This may be due to the belief that feminine female perpetrators are considered less blameworthy because they are in danger of greater physical injury, although masculine women who deviate from their gender identity and men (despite masculinity/femininity) are in less danger of physical injury and therefore more deserving of blame. Interestingly, our prediction that masculine males would be perceived as inflicting greater injury to the victim was not supported. Rather, victims' fear of injury was significantly lower when the perpetrator was a feminine female. This finding suggests that it is not just the idea of a female who is incapable or unlikely to inflict severe 
pain or injury, but instead, it is the idea of femininity associated with our gender identity that lead many to believe women are unlikely or unable to perpetrate injury. Aggression is not a typical stereotyped expectation associated with the female gender role.

Last, in an effort to determine whether the extent to which a perpetrator's ability to arouse fear of injury in the victim played a significant role in attributions of blame, we found that when victims' fear of injury was statistically controlled, the effect size for the perpetrator sex by victim sex interaction was significantly reduced and the perpetrator sex by masculinity/femininity interaction was eliminated. This result provides evidence that discrepancies typically found in attributions of blame as a function of perpetrator and victim sex are significantly driven by the belief that women (particularly feminine women) will incur greater injury.

Research consistently finds that female-perpetrated IPV is not perceived the same as male-perpetrated IPV. The results of this study provide insights and support of gendered protectionist stereotypes as an explanation for differential treatment of men and women in partner abuse situations. Stereotyped assumptions such as women need protection from men and men are stronger and unlikely to experience social or psychological effects from abuse (Douglas \& Hines, 2011) can lead to biased perceptions of blame, which negate or dismiss the fact that men and women both suffer negative consequences of IPV. This further leads to discrimination and access to resources to victims of IPV who are not heterosexual female.

We recognize our study findings are limited in a number of respects. First, although we had both a student and online sample, they were of limited ethnic diversity. Similarly, the targets were all White. It would be important to see how sex, gender identity, and ethnicity all play a role in perceptions of IPV. In addition, our decision to use a case of a more severe assault may have affected results. Future research should study whether victims' fear of injury would actually play such a key role in less severe or more ambiguously initiated depictions of IPV.

In conclusion, although sex disparities in perceptions of domestic assault are evident within the public and criminal justice system, our research sheds light on some of the reasons why this may occur. These results further demonstrate our societal need to understand that IPV is IPV, despite sex or sexual orientation of the perpetrator, and that all victims deserve to be treated equally. To do so, we must rely more on changing community attitudes that ultimately affect access to resources for victims and criminal justice response.

\section{Acknowledgements}

The authors would like to thank Brandon Fisher for his thoughtful editorial suggestions.

\section{Declaration of Conflicting Interests}

The author(s) declared no potential conflicts of interest with respect to the research, authorship, and/or publication of this article.

\section{Funding}

The author(s) received no financial support for the research, authorship, and/or publication of this article.

\section{References}

Black, M. C., Basile, K. C., Breiding, M. J., Smith, S. G., Walters, M. L., Merrick, M. T., . . Stevens, M. R. (2011). The National Intimate Partner and Sexual Violence Survey (NISVS): 2010 summary report. Atlanta, GA: 
National Center for Injury Prevention and Control, Center for Disease Control and Prevention. Retrieved from http://www.cdc.gov/ViolencePrevention/pdf/NISVS Report2010-a.pdf Google Scholar

Douglas, E. M., Hines, D. A. (2011). The helpseeking experiences of men who sustain intimate partner violence: An overlooked population and implications for practice. Journal of Family Violence, 26, 473-485. doi:10.1111/j.1741-3737.2005.00209.x Google Scholar, Crossref, Medline

Felson, R. B., Feld, S. L. (2009). When a man hits a woman: Moral evaluations and reporting violence to the police. Aggressive Behavior, 35, 477-488. doi:10.1002/ab.20323 Google Scholar, Crossref, Medline

Hamby, S., Jackson, A. (2010). Size does matter: The effect of gender on perceptions of dating violence. Sex Roles, 63, 324-331. Google Scholar, Crossref

Katz, J., Arias, I. (2001). Women's attributions for hypothetical dating violence: Effects of partner alcohol and violence severity. Journal of Applied Social Psychology, 31, 1458-1473. Google Scholar, Crossref

Langhinrichsen-Rohling, J., Misra, T. A., Selwyn, C., Rohling, M. L. (2012). Rates of bi-directional versus unidirectional intimate partner violence across samples, sexual orientations, and race/ethnicities: A comprehensive review. Partner Abuse, 3, 199-230. doi:10.1891/1946-6560.3.2.199 Google Scholar, Crossref

Laroche, D. (2005). Aspects of the context and consequences of domestic violence-Situational couple violence and intimate terrorism in Canada in 1999. Quebec City, Canada: Government of Quebec. Google Scholar

Rhatigan, D. L., Stewart, C., Moore, T. M. (2011). Effects of sex and confrontation on attributions of femaleperpetrated intimate partner violence. Sex Roles, 64, 875-887. doi:10.1007/s11199-011-9951-2. Google $\underline{\text { Scholar, }}$ Crossref

Russell, B. L., Ragatz, L., Kraus, S. W. (2012). Expert testimony of the battered person syndrome, defendant gender, and sexual orientation in a case of duress: Evaluating legal decisions. Journal of Family Violence, 27, 659-670. Google Scholar, Crossref

Seelau, S. M., Seelau, E. P. (2005). Sex-role stereotypes and perceptions of heterosexual, gay, and lesbian domestic violence. Journal of Family Violence, 20, 363-371. doi:10.1007/s10896-005-7798-4 Google $\underline{\text { Scholar }}, \underline{\text { Crossref }}$

Spence, J. T., Helmreich, R. L. (1979). Masculinity and femininity: Their psychological dimensions, correlates and antecedents. Austin: University of Texas Press. Google Scholar

Straus, M. A. (2010). Thirty years of denying the evidence on gender symmetry in partner violence: Implications for prevention and treatment. Partner Abuse, 1, 332-363. Google Scholar, Crossref

West, C. M. (2012). Partner abuse in ethnic minority and gay, lesbian, bisexual and transgender populations. Partner Abuse, 3, 336-357. Google Scholar, Crossref 


\section{Author Biographies}

Brenda Russell, PhD, is a professor and social psychologist at Penn State Berks. Her interests include perceptions of victims and perpetrators of domestic violence, rape, and sexual harassment, and how gender and sexual orientation play a role in evaluating perpetrators and victims.

Shane W. Kraus, PhD, is a licensed psychologist and fellow at the Veterans Health Administration at Yale University, New Haven, Connecticut.

Kristine M. Chapleau, PhD, joined the faculty of Indiana University School of Medicine in 2011 and provides psychotherapy to adults. Her research interests include understanding the role of power and status in the commission and perception of sexual violence.

Debra Oswald, PhD, is an associate professor and social psychologist at Marquette University and applies social psychological theories to understanding social issues. Her two areas of focus include social stigma and interpersonal relationships. 